\title{
The Comparison About Private Enterprises Between Shandong Province and Zhejiang Province
}

\author{
Xinyu Zhuang ${ }^{1, *}$ \\ ${ }^{I}$ College of Liberal Arts and Science, University of Connecticut, Storrs, CT, 06269, the United States of America, \\ *Xinyu Zhuang. Email: xinyuzhuang123@gmail.com
}

\begin{abstract}
Private enterprises are one of the most important pillars for any economy. There are several huge differences in regards of private enterprises between Shandong province and Zhejiang province. The differences are mainly shown out via the different industries that the private enterprises work in, the different origins of the private enterprises, and the different working philosophies of the private enterprises.
\end{abstract}

Keywords: private enterprises, industries, origins, and philosophies

\section{THE SITUATION ABOUT PRIVATE ENTERPRISES FOR ZHEJIANG PROVINCE AND SHANDONG PROVINCE}

The discussions between southern part of China and northern part of China, which are the two relatively developed areas in China, are always hot topics in economic field. Although they are both relatively developed, there are huge differences with their economy structures. It is not a secret that private enterprises are widely different based on different locations in China. Especially the southern part and the northern part, which are the two most striking comparisons; for instance, Shandong province, as a representative of northern part of China, has its more than a half GDP contributed by state-owned enterprises; by comparison Zhejiang province, as a representative of southern part of China, has its more a half GDP contributed by private enterprises. In other words, the state-wined companies are the major part in Shandong province's economy, and the private enterprises are the major part in Zhejiang province's economy. Not only the major GDP contributors for the two areas are significantly different, but the dominate private enterprise industries between Zhejiang province and Shandong province's in both scale and the industry. [1] Taking Wenzhou, Zhejiang province as an example, after the start of recover in 1978 and the enterprises in shoemaking industry became develop rapidly. It rose from original 19 shoe making enterprises in 1978 to 99 shoemaking enterprises in1981 in one district of Wenzhou alone. And now it is the most important shoe making industry base of the country. (Zuhui Huang, 2006) By comparison, a lot of private enterprises in Shandong province focus on agricultural industry and processing raw agricultural products.

With the trend that private enterprises in Zhejiang province developing stronger and more active, the weakness of Shandong province in terms of private enterprises are more obvious. And, also, people may raise questions about why there are more private enterprises in Zhejiang province than Shandong province. There are a lot of reasons for causing the huge difference in terms of private enterprises' developments between Shandong province and Zhejiang province, such as history reason, traditional philosophies' differences, governments' regulation from ancient China, and the distributions for natural resources, etc. Those factors could have significant impact on those people but some of them could also mix to enhance or make people to take strategies differently for each group of people. Those distinct factors make those people to make strategies in different methods when they are required to make decisions.

You may consider that since the private enterprises are developing differently in both Zhejiang province and Shandong province, how do they influence local people and local economy. According to statistical data, from 2007 to 2012 the gap between the increasing rate for northern part of China's GDP and the increasing rate for southern part of China's GDP is less than 0.5\%; however, the situation has changed since 2013. The increasing rate for Southern part of China GDP became faster than northern part of China and even in 2016 the 
increasing rate gap between southern part of China and northern part of China is about 2\%. Since Shandong province is one of the most important part of northern China and Zhejiang province is one of the most important part in southern China, we could predict that Zhejiang's increasing rate about GDP became faster than Shandong province's. That is one of the consequences for the different developments of private enterprises.

There are several questions that this passage is trying to explore, illustrate and explain: what are the status and the differences between Zhejiang province's and Shandong province's private enterprises? What factors could explain their private enterprises' unique developments? What are the consequences after the two provinces have formed the current private enterprises pattern? Last but not the least, how to modify the economic structure which enhance the economic developments for each province?

\section{REASON EXPLORATION}

The huge differences between Shandong province and Zhejiang province on private economy attract people to explore the reasons behind. According data from bureau of statics in both Shandong province and Zhejiang province, there is a trend that the proportions of GDPs that were contributed by private enterprises were increasing in both provinces. However, although they were increasing, there is a huge difference in extent. [2] From 2000 to 2003, the proportion of GDP that was contributed by private enterprises increased from $31.6 \%$ to $40.3 \%$ in Shandong province; by comparison, GDP from private enterprises increased from $47.1 \%$ to $59.5 \%$ in Zhejiang province. With being said the huge differences in private enterprises, the economy structure seems to be a breakthrough (Chunhong Su, Jian Wei 2005). They further explored the differences and listed some evident features: the first one is that the origins for those private enterprises are different in the two provinces: most private enterprises in Shandong province are original state-owned enterprises or agricultural industrialization, there are 101 original state-owned enterprises were changed to private enterprises out of 110 state-owned enterprises by the end of 2002 in Shandong province (Shandong bureau of statistics, 2002); while most Zhejiang province's private enterprises are started based in villages (Zhejiang bureau of statistics, 2003), and are in manufacturing industries. The second is that with the different origins, the development methods are different as well. In Shandong province, the private enterprises are enhanced by state-owned enterprises; by contrast, private enterprises would be the leader for Zhejiang province's economy. Overall, the governments play extremely important roles in the economic differences in the two provinces. Government in Shandong province would lead private enterprises in local economy development, while private enterprises are the most considerable part in Zhejiang's local economy.

Furthermore, the non-governmental origination is also a factor in the development progress between Zhejiang province and Shandong province. [4] Jun Liu did a research in 2008 which explores the nongovernmental origination in both provinces. Jun focused the research on Qing Dynasty, private enterprises prospered for various reasons, such as for the country, for the wealth, etc. Jun mentioned that from Song Dynasty, the trend of clusters based on ethic had been seen a lot in southern party, including Zhejiang province. Additionally, ever since recording begins of China history, the most central governments were in northern parts of China, which means that the control in northern China, including Shandong province, from the government is more intensive than southern China. With the development of the non-governmental originations in southern part, the governments' functions were diminished. Originations such as private banks or cultural organizations were developing. Those originations could provide more freedom to private enterprises' developments; by comparison, there are not so many private originations like that due to the proximity to the central government.

Despite the governments' significant effects on private enterprises, the ethic aspect is unavoidable when it comes to the private enterprises. With Yaqing Yang and Shouye Liu's research on the relationship of among entrepreneur sprit (2019), government, and private enterprises, we could know the iceberg of the roles of ethics for private entrepreneurs. He claimed that in Zhejiang province, private entrepreneurs have some unique features that stand them out from other private entrepreneurs. The first and the foremost feature is the sprit of brave to create. That means they could start without any example for them. They are good at creating. There is an example from Wei Jian and Chunhong su's research (2004) that could prove the feature for Zhejiang entrepreneurs. In the last century seventies, the major industry in China back then was agricultural industry. However, Zhejiang province is not the place for agriculture due to the lack of farming land and natural resources. To survive, they started their exploration for new methods to live. That is the private enterprises. Both the fact and the ethic with their births drives them to make lives on their own. Shandong province is known for the home of Confucius, who is the firm advocator of rule system and is known for his conservative ethics. His impact the whole China's ethic evolution from ancient China to contemporary China, especially in Shandong province, made a great difference. By comparison with Zhejiang people, people in Shandong province tend to be conservative and tend to be honest about the local authority without thinking the content, which is also a part of the reasons for different state-owned enterprises' status in the two 
provinces. While private enterprises developed in considerable scale in Zhejiang province in last century seventies; Shandong people sticked to agricultural industry with the consideration that agricultural industry was still enough to feed people in Shandong province. Therefore, the private enterprises in Shandong province developed slower than Zhejiang province's. And with the different ethics the two groups people's conductions are different in the later development.

\section{DATA ANALYSIS}

In this part I would show the analysis on both Zhejiang province and Shandong province's economy and the analysis on the enterprise, including state-owned enterprises and private enterprises.

First and foremost, one of the most important indexes for economy is GDP. To show clearly about the GDP information in regards of specific industry, I have searched considerable data and plug it into the later passages.

Table 1 Zhejiang province's GDP from 1978 to 2018

\begin{tabular}{|c|c|c|c|c|c|}
\hline Year & GDP & Primary Industry & Second Industry & Tertiary Industry & $\begin{array}{c}\text { Tertiary Industry } \\
\text { Ratio }\end{array}$ \\
\hline 1978 & 123.72 & 47.09 & 53.52 & 23.11 & 0.186792758 \\
\hline 1979 & 157.75 & 67.56 & 64.07 & 26.12 & 0.165578447 \\
\hline 1980 & 179.92 & 64.61 & 84.07 & 31.24 & 0.173632726 \\
\hline 1981 & 204.86 & 69.06 & 94.68 & 41.12 & 0.200722445 \\
\hline 1982 & 234.01 & 84.88 & 98.44 & 50.69 & 0.216614675 \\
\hline 1983 & 257.09 & 82.89 & 113.12 & 61.08 & 0.23758217 \\
\hline 1984 & 323.25 & 104.40 & 141.48 & 77.37 & 0.239350348 \\
\hline 1985 & 429.16 & 123.88 & 198.91 & 106.37 & 0.247856277 \\
\hline 1986 & 502.47 & 136.29 & 230.89 & 135.29 & 0.269249905 \\
\hline 1987 & 606.99 & 159.41 & 281.47 & 166.11 & 0.27366184 \\
\hline 1988 & 770.25 & 195.68 & 354.39 & 220.18 & 0.285855242 \\
\hline 1989 & 849.44 & 210.95 & 386.25 & 252.24 & 0.296948578 \\
\hline 1990 & 904.69 & 225.04 & 408.18 & 271.47 & 0.300069637 \\
\hline 1991 & 1089.33 & 245.22 & 494.11 & 350.00 & 0.321298413 \\
\hline 1992 & 1375.70 & 262.67 & 653.43 & 459.60 & 0.334084466 \\
\hline 1993 & 1925.91 & 315.96 & 983.96 & 625.99 & 0.325035957 \\
\hline 1994 & 2689.28 & 438.65 & 1398.12 & 852.51 & 0.317003064 \\
\hline 1995 & 3557.55 & 549.96 & 1854.52 & 1153.07 & 0.324119127 \\
\hline 1996 & 4188.53 & 594.93 & 2232.17 & 1361.43 & 0.325037662 \\
\hline 1997 & 4686.11 & 618.90 & 2554.57 & 1512.64 & 0.322792252 \\
\hline 1998 & 5052.62 & 609.30 & 2766.94 & 1676.38 & 0.331784302 \\
\hline 1999 & 5443.92 & 606.31 & 2974.74 & 1862.87 & 0.342192758 \\
\hline 2000 & 6141.03 & 630.98 & 3273.93 & 2236.12 & 0.364127842 \\
\hline 2001 & 6898.34 & 659.78 & 3572.88 & 2665.68 & 0.3864234 \\
\hline 2002 & 8003.67 & 685.20 & 4090.48 & 3227.99 & 0.40331373 \\
\hline 2003 & 9705.02 & 717.85 & 5096.38 & 3890.79 & 0.400904893 \\
\hline 2004 & 11648.70 & 814.10 & 6250.38 & 4584.22 & 0.393539193 \\
\hline 2005 & 13417.68 & 892.83 & 7164.75 & 5360.10 & 0.399480387 \\
\hline 2006 & 15718.47 & 925.10 & 8511.51 & 6281.86 & 0.399648312 \\
\hline 2007 & 18753.73 & 986.02 & 10154.25 & 7613.46 & 0.405970439 \\
\hline 2008 & 21462.69 & 1095.96 & 11567.42 & 8799.31 & 0.409981694 \\
\hline 2009 & 22998.24 & 1163.08 & 11860.16 & 9975.01 & 0.433729277 \\
\hline 2010 & 27747.65 & 1360.56 & 14187.36 & 12199.74 & 0.439667503 \\
\hline 2011 & 32363.38 & 1583.04 & 16331.27 & 14449.07 & 0.446463565 \\
\hline 2012 & 34739.13 & 1667.88 & 17000.09 & 16071.16 & 0.462624136 \\
\hline 2013 & 37756.58 & 1760.34 & 18047.52 & 17948.72 & 0.475379921 \\
\hline 2014 & 40173.03 & 1777.18 & 19175.06 & 19220.79 & 0.478450095 \\
\hline 2015 & 42886.49 & 1832.91 & 19711.67 & 21341.91 & 0.497637135 \\
\hline 2016 & 47251.36 & 1965.18 & 21194.61 & 24091.57 & 0.509859822 \\
\hline 2017 & 51768.26 & 1933.92 & 22232.08 & 27602.26 & 0.533188869 \\
\hline 2018 & 56197.15 & 1967.01 & 23505.88 & 30724.26 & 0.546722743 \\
\hline
\end{tabular}

(The Tertiary Industry ration= Tertiary Industry/ GDP; [6] sources are from Zhejiang province Bureau of Statistics, statistical yearbook 2019; unit is 100 million yuan) 
There are several noteworthy pieces of data in the table above. As I have mentioned that Zhe Jiang province is not an agricultural province like Shan Dong province does, instead people in Zhe Jiang province explores their methods to prosper themselves. The table shows that from the beginning the primary industry occupies about half of GDP; by comparison, the tertiary industry, which is the concentration of private enterprises only occupies about $19 \%$. However, as times goes, the situation has changed. The trend of development of the tertiary industry begins from the beginning of the record, which is 1978 to the end of the record, which is 2018. The contribution for GDP from the tertiary industry firstly increased from 19\% 1978 to $27 \%, 1986$. Then, the trend did not even be diminished, and continuously increased till the end of the record to $55 \%$, which is in 2018. With being said in the first part of the passage that, Zhejiang is not rich in natural resources, the primary industry was not developed well; as a result, people in Zhejiang province, with their adventurous spirts, they explored the tertiary industry and developed tertiary industry to adapt themselves to the nature.

Table 2 Shandong province's GDP from 1952 to 2018

\begin{tabular}{|c|c|c|c|c|c|}
\hline Year & GDP & Primary Industry & Second Industry & Tertiary Industry & Tertiary Industry Ratio \\
\hline 1978 & 43.81 & 29.55 & 7.27 & 6.99 & 0.159552614 \\
\hline 1979 & 57.78 & 35.52 & 11.42 & 10.84 & 0.187608169 \\
\hline 1980 & 61.39 & 31.95 & 17.59 & 11.85 & 0.19302818 \\
\hline 1981 & 64.38 & 30.42 & 16.91 & 17.05 & 0.264833799 \\
\hline 1982 & 86.25 & 42.24 & 28.96 & 15.05 & 0.174492754 \\
\hline 1983 & 126.31 & 52.23 & 53.71 & 20.37 & 0.161269892 \\
\hline 1984 & 166.19 & 65.54 & 75.31 & 25.34 & 0.152476082 \\
\hline 1985 & 225.45 & 75.06 & 119.35 & 31.04 & 0.137680195 \\
\hline 1986 & 251.6 & 91.12 & 127.68 & 32.8 & 0.13036566 \\
\hline 1987 & 292.13 & 106.43 & 146.11 & 39.59 & 0.135521857 \\
\hline 1988 & 346.57 & 132.21 & 155.41 & 58.95 & 0.170095507 \\
\hline 1989 & 395.38 & 154.07 & 166.05 & 75.26 & 0.190348525 \\
\hline 1990 & 459.83 & 185.57 & 178.75 & 95.51 & 0.207707196 \\
\hline 1991 & 581.56 & 222.13 & 239.27 & 120.16 & 0.206616686 \\
\hline 1992 & 680.46 & 235.96 & 293.07 & 151.43 & 0.222540634 \\
\hline 1993 & 742.05 & 252.73 & 313.21 & 176.11 & 0.237329021 \\
\hline 1994 & 892.29 & 287.31 & 384.57 & 220.41 & 0.247016105 \\
\hline 1995 & 1117.66 & 331.94 & 497.1 & 288.62 & 0.258235957 \\
\hline 1996 & 1293.94 & 359.14 & 579.65 & 355.15 & 0.274471768 \\
\hline 1997 & 1511.19 & 425.29 & 635.98 & 449.92 & 0.297725633 \\
\hline 1998 & 1810.54 & 521.85 & 745.9 & 542.79 & 0.299794536 \\
\hline 1999 & 2196.53 & 534.62 & 999.11 & 662.8 & 0.301748667 \\
\hline 2000 & 2770.37 & 596.63 & 1355.71 & 818.03 & 0.295278248 \\
\hline 2001 & 3844.5 & 775.03 & 1891.43 & 1178.04 & 0.306422162 \\
\hline 2002 & 4953.35 & 1010.13 & 2355.78 & 1587.44 & 0.32047806 \\
\hline 2003 & 5883.8 & 1200.17 & 2784.09 & 1899.54 & 0.322842381 \\
\hline 2004 & 6537.07 & 1195 & 3147.37 & 2194.7 & 0.335731452 \\
\hline 2005 & 7021.35 & 1215.81 & 3408.06 & 2397.49 & 0.341457127 \\
\hline 2006 & 7493.84 & 1221 & 3644.32 & 2628.52 & 0.350757422 \\
\hline 2007 & 8337.47 & 1268.57 & 4164.45 & 2904.45 & 0.348361074 \\
\hline 2008 & 9195.04 & 1359.49 & 4556.01 & 3279.53 & 0.35666294 \\
\hline 2009 & 10275.5 & 1390 & 5184.98 & 3700.52 & 0.360130407 \\
\hline 2010 & 12078.15 & 1480.67 & 6485.05 & 4112.43 & 0.340485091 \\
\hline 2011 & 15115.24 & 1778.45 & 8562.38 & 4774.41 & 0.315867297 \\
\hline 2012 & 18496.99 & 1963.51 & 10595.22 & 5938.26 & 0.321039261 \\
\hline 2013 & 22059.66 & 2138.9 & 12716.93 & 7203.83 & 0.326561243 \\
\hline 2014 & 25982.63 & 2501.03 & 14839.13 & 8642.47 & 0.332624911 \\
\hline 2015 & 31212.34 & 2983.61 & 17839.09 & 10389.64 & 0.332869628 \\
\hline 2016 & 34219.28 & 3194.38 & 19219.83 & 11805.07 & 0.344983004 \\
\hline 2017 & 39571.2 & 3538.73 & 21643 & 14389.47 & 0.363634916 \\
\hline 2018 & 45874.95 & 3909.28 & 24538.45 & 17427.22 & 0.379885319 \\
\hline
\end{tabular}

(The Tertiary Industry ration= Tertiary Industry/ GDP; [5] sources are from Shandong province Bureau of Statistics, statistical yearbook 2019; unit is 100 million yuan)

Although, Shandong province's tertiary industry has also developed a lot from the record about $16 \%$ in 1952 to about $50 \%$ in 2018 , there is still a huge gap by comparison with Zhejiang province's development. From the table 1.1 and table 1.2 we could find that the Shandong province's tertiary industry developed later 
than Zhejiang province did. When Zhejiang province's tertiary industry could beat the primary industry in terms of GDP in 1986, Shandong province's GDP was still mainly supported by primary industry and secondary industry until 1989, when the

tertiary industry production vale broke even with primary industry's. One of the reasons for that Shandong province developed tertiary industry later than Zhejiang industry could be the effects from
Confucius philosophy, which advocate to be conservative. And the reason for the delayed development of tertiary industry is also one of the reasons for people in Shandong province are less likely to start a enterprise than people in Zhejiang province.

Besides of the GDP, which is significant for economy, enterprises are, instead, the really main course for my passage.

Table 3 The amount of enterprises within Shandong province, from 2010 to 2017.

\begin{tabular}{|c|c|c|c|c|c|c|c|c|}
\hline Year & 2010 & 2011 & 2012 & 2013 & 2014 & 2015 & 2016 & 2017 \\
\hline $\begin{array}{c}\text { Total } \\
\text { Amount of } \\
\text { Organzation }\end{array}$ & 773752 & 832443 & 906064 & 825706 & 1042809 & 1269917 & 1652065 & 2014790 \\
\hline Enterprises & 592359 & 649509 & 722344 & 616676 & 819036 & 1048470 & 1344176 & 1675975 \\
\hline $\begin{array}{c}\text { The } \\
\text { Percentage } \\
\text { of } \\
\text { Enterprises }\end{array}$ & 0.765567 & 0.780244 & 0.797233 & 0.746847 & 0.785413 & 0.825621 & 0.813634 & 0.831836 \\
\hline
\end{tabular}

(The Percentage of Enterprises =Enterprises/Total Amount for Organizations, [5] sources are from Shandong Bureau of Statistics; statistical yearbook 2019)

As I have mentioned a lot in the previous parts that people Shandong province are less likely to start enterprises, the data is showing the details in regards of the amount of enterprises in Shandong province since 2011 to 2017. According to the table 2.1, we could tell that the amount of enterprises is increasing gradually from 592359 to 1675975 , which is a dramatic change. The amount was almost tripled. And the ratio of enterprises among all organizations (foundations, governmental administrations, non-profitable organizations, etc.) has risen from about $77 \%$ to $83 \%$. That is a huge improvement.

Table 4 The amount of enterprises within Zhejiang province, from 2010 to 2017.

\begin{tabular}{|c|c|c|c|c|c|c|c|c|}
\hline Year & 2010 & 2011 & 2012 & 2013 & 2014 & 2015 & 2016 & 2017 \\
\hline $\begin{array}{c}\text { Total Amount } \\
\text { of } \\
\text { Organization }\end{array}$ & 685506 & 778194 & 865154 & 1014357 & 1235664 & 1346364 & 1497168 & 1792469 \\
\hline Enterprises & 570270 & 659003 & 739040 & 867919 & 1080452 & 1189601 & 1307847 & 1599314 \\
\hline $\begin{array}{c}\text { The } \\
\text { Percentage } \\
\text { of } \\
\text { Enterprises }\end{array}$ & 0.831896 & 0.846836 & 0.854229 & 0.855635 & 0.87439 & 0.883566 & 0.873547 & 0.892241 \\
\hline
\end{tabular}

(The Percentage of Enterprises=Enterprises/Total Amount of Organizations; [6] sources are from Zhejiang Bureau of Statistics; statistical yearbook

2012-2019.)(For The Percentage of Enterprises independent two-sample t-test $=-5.5839, \mathrm{p}=0<0.01$ )

From the table 2.3 we could easily get the information that Zhejiang's the percentage of enterprises is already about $83 \%$ in 2010; by comparison with Shandong province's enterprises with the same time, that is 6 percent more. And it is more note worthy that the percentage of Zhejiang province's enterprises in 2010 is almost the same with the percentage of enterprises in Shandong provinces in 2017. That is a significant gap. From 2010 to 2017, the proportion has increased from about $83 \%$ to $89 \%$, the amount rocket from 570270 to 1599314 , which means it is almost tripled as well as the amount of enterprises in Shandong province.
After we have overviewed the data of both Shandong province and Zhejiang province's percentages of enterprises in regards of all organizations and the amounts of enterprises, it is seems that the results are hardly ever help us to research the gap on the development of private enterprises. However, we still have not take the factor of population into the research.

As I have mentioned that people in Zhejiang province are more likely to start enterprises than people in Shandong province, population then has become a factor that cannot be ignored.

Table 5 Shandong Province population and Enterprise per person from 2010 to 2017

$$
\text { Year }
$$$$
2010
$$

2011

2012

2013

2014

2015

2016




\begin{tabular}{|l|c|c|c|c|c|c|c|c|}
\hline $\begin{array}{c}\text { Population(10 } \\
\text { thousand) }\end{array}$ & 9579 & 9637 & 9685 & 9733 & 9789 & 9847 & 9947 & 10006 \\
\hline $\begin{array}{c}\text { Enterprise per } \\
\text { person }\end{array}$ & 0.006184 & 0.00674 & 0.007458 & 0.006336 & 0.008367 & 0.010648 & 0.013513 & 0.01675 \\
\hline
\end{tabular}

(Enterprise per person= enterprise/ (population*10000); [5] sources are from Shandong Bureau of Statistics; statistical yearbook 2019)

Table 6 Zhejiang Province population and Enterprise per person from 2010 to 2017

\begin{tabular}{|c|c|c|c|c|c|c|c|c|}
\hline Year & 2010 & 2011 & 2012 & 2013 & 2014 & 2015 & 2016 & 2017 \\
\hline $\begin{array}{c}\text { Population(10 } \\
\text { thousand) }\end{array}$ & 4747.95 & 4781.31 & 4799.34 & 4826.89 & 4859.18 & 4873.34 & 4910.85 & 4957.63 \\
\hline $\begin{array}{c}\text { Enterprise } \\
\text { per person }\end{array}$ & 0.012011 & 0.013783 & 0.015399 & 0.017981 & 0.022235 & 0.02441 & 0.026632 & 0.03226 \\
\hline
\end{tabular}

(Enterprise per person= enterprise/(population*10000); [6] sources are from Zhejiang Bureau of Statistics; statistical yearbook 2019.)

(For enterprise per person independent two-sample $\mathrm{t}$-test $=-3.9128 \mathrm{p}=0.0008<0.01$ )

Enterprise per person that I employed to analyze date aims at showing not only the objective number of enterprises, but also the likelihood of starting enterprises. Although we could see that both provinces have the similar data in terms of the percentages of enterprises and the amounts of enterprises, the likelihood of starting enterprises are different. Shandong province's enterprise per person is almost half of the Zhejiang province's enterprise per person through 2010 to 2017, which proves us that people in Zhejiang are more likelihood to start enterprises. The reason for Shandong province that there are almost as many enterprises as in Zhejiang province, is Shandong province's population is about twice as much as Zhejiang province.

Gross industrial output value is another index in statistics, which could refer to the level of secondary industry's production. For both Zhejiang province and Shandong province, the contribution from secondary industry is unignored since there are a lot of people decide to start enterprises in secondary industry and the GDP it brings to the local economy. Therefore, in the next two tables, I would show the secondary industry's development of secondary industry.

Table 7 Zhejiang Province's industry gross output value from 2007 to 2017

\begin{tabular}{|c|c|c|c|c|c|}
\hline Year & $\begin{array}{c}\text { Gross Industrial } \\
\text { Output Value } \\
(100 \text { millioon } \\
\text { yuan) }\end{array}$ & $\begin{array}{c}\text { State- } \\
\text { owned }\end{array}$ & Private & $\begin{array}{c}\text { The Percentage of } \\
\text { state-owned (\%) }\end{array}$ & $\begin{array}{c}\text { The Percentage of } \\
\text { private } \%)\end{array}$ \\
\hline 2007 & 36073.93 & 2349.06 & 33724.87 & 0.065118 & 0.934882 \\
\hline 2008 & 40832.1 & 2609.2 & 38222.9 & 0.063901 & 0.936099 \\
\hline 2009 & 41035.29 & 2786.63 & 38248.66 & 0.067908 & 0.932092 \\
\hline 2010 & 51394.2 & 3331.26 & 48062.94 & 0.064818 & 0.935182 \\
\hline 2011 & 56406.06 & 3331.27 & 53074.79 & 0.059059 & 0.940941 \\
\hline 2012 & 59124.16 & 3331.28 & 55792.88 & 0.056344 & 0.943656 \\
\hline 2013 & 62980.3 & 3331.29 & 59649.01 & 0.052894 & 0.947106 \\
\hline 2014 & 67039.8 & 3331.3 & 63708.5 & 0.049691 & 0.950309 \\
\hline 2015 & 66819 & 3331.31 & 63487.69 & 0.049856 & 0.950144 \\
\hline 2016 & 68953.4 & 3331.32 & 65622.08 & 0.048313 & 0.951687 \\
\hline 2017 & 66328 & 3331.33 & 62996.67 & 0.050225 & 0.949775 \\
\hline
\end{tabular}

( [6] Sources are from Zhejiang Bureau of Statistics, statistical yearbook 2013-2019)

The Zhejiang province's industry gross output value illustrates that from 2007 to 2017 the value has been increasing from original 3673.93 in 2007 to 66328 in 2017. The increasing trend did not stop from the beginning of the record to the end of to record. There is a noteworthy piece of data, which is the private enterprises takes the overwhelming proportion of the secondary industry, and the proportion has also increased from about $93 \%$ to about $95 \%$. 
Table 8 Shandong province industry output value from 2007 to 2017

\begin{tabular}{|c|c|c|c|c|c|}
\hline Year & $\begin{array}{c}\text { Gross Industrial } \\
\text { Output Value } \\
(100 \text { millioon } \\
\text { yuan) }\end{array}$ & $\begin{array}{c}\text { State- } \\
\text { owned }\end{array}$ & Private & $\begin{array}{c}\text { The Percentage of } \\
\text { state-owned } \%)\end{array}$ & $\begin{array}{c}\text { The Percentage of } \\
\text { private }(\%)\end{array}$ \\
\hline 2007 & 54428.27 & 2988.11 & 51440.16 & 0.0549 & 0.9451 \\
\hline 2008 & 62958.53 & 4577.21 & 58381.32 & 0.072702 & 0.927298 \\
\hline 2009 & 71209.42 & 4074.70 & 67134.72 & 0.057221 & 0.942779 \\
\hline 2010 & 83851.40 & 5486.12 & 78365.28 & 0.065427 & 0.934573 \\
\hline 2011 & 99504.98 & 6200.76 & 93304.22 & 0.062316 & 0.937684 \\
\hline 2012 & 114707.29 & 5022.12 & 109685.17 & 0.043782 & 0.956218 \\
\hline 2013 & 129906.01 & 4250.08 & 125655.93 & 0.032717 & 0.967283 \\
\hline 2014 & 141415.02 & 4262.15 & 137152.87 & 0.030139 & 0.969861 \\
\hline 2015 & 145964.20 & 4547.07 & 141417.13 & 0.031152 & 0.968848 \\
\hline 2016 & 150705.13 & 3895.70 & 146809.43 & 0.02585 & 0.97415 \\
\hline 2017 & 137440.74 & 2275.98 & 135164.76 & 0.01656 & 0.98344 \\
\hline
\end{tabular}

( [5] Sources are from Shandong Bureau of Statistics; statistical yearbook 2019)

(For state-owned: Independent two-sample t-test $=3.3908, \mathrm{p}=0.0015<0.01$; for The Percentage of state-owned independent two-sample t-test=$2.1802, \mathrm{p}=0.0210<0.05)$

With being analyzed Zhejiang province's gross industrial output value, Shandong province's data shows a more developed secondary industry. The value rocketed from 54428.27 in 2007 to 137440.74 in 2017. Impressive data is that the proportion of private enterprises was about $94 \%$ in 2007 which is about the same ratio as Zhejiang province's in 2017. And Shandong province's private enterprises takes up about 98\% secondary industry in 2017.

After all the analysis there are several factors, which contributed a lot to the regional private enterprises' developments in both Zhejiang province and Zhejiang province. The first one is the influence from government that begins from the history record. Since Zhejiang province is further from the central government than Shandong province, the control from central government is less. That makes a friendly circumstance for the formation of private organization, such as private bank, which support private enterprises in Qing dynasty. The second factor is the influence from the local cultures. Shandong province is the home of Confucius philosophy, which advocates people should be more conservative in actions and follow rules, from governments, parents, etc. With the effects of Confucius philosophy people in Shandong province are more conservative when they are required to take strategies. By comparison, people in Zhejiang province holds the spirts to be brave to create and innovate. That drives them to prefer to start private enterprises than work for others. The third influences are the natural factor. In 2017 Shandong province's industrial output value is about $137,440,00$ million and is contributed by private enterprises for about $98 \%$; by comparison Zhejiang province's industrial output value is about $663,280,0$ million and is contributed by private enterprises for about $93 \%$. The natural resources limit the development of secondary industry. Therefore, people in Zhejiang province start business with their entrepreneurship in the tertiary industry. Last but not the least, private enterprises in Zhejiang province tend to develop in cluster form and to develop in highly extent of specialization, such as Wenzhou, is the base of shoemaking industry of China, but there are also lots of leather enterprises nearby. Whereas private enterprises in Shandong province do not show a strong trend of clusters.

\section{FLAW ABOUT THE PASSAGE}

There is a flaw in this passage, which I cannot handle; that is the influence of cultures for both Zhejiang province and Shandong province. Although I can know that how the cultures affect the local people's minds, and the private enterprises, I cannot find an index to show the extent of the cultures' influence.

\section{5. sCONCLUSION}

The aims that I analyzed the development of the private enterprises in both Zhejiang province and Shandong province is to make them stand out the potential factors that affect the development of private enterprises, which is the absolutely core pillar for an economy. That might be helpful for the development of 
private enterprises and might be helpful for the economy.

The first factor is the weakness part in Shandong province, which is the advantage in Zhejiang province, the cultures. To be brave to start the business, like the Zhejiang people's sprit.

The second factor is the government effects on the economy. Private enterprises are highly needed as a core element for an economy. Governments might take strategies like providing flexible policies on financial support to motivate the development for local private enterprises.

The third factor is the formation of business alliances like the example of Wenzhou, which formed a highly specialized in shoemaking factory cluster and attracted lots of business related to the shoemaking industry to locate nearby. That might be another effective method for the development for local private enterprises.

Private economy is mainly shown via the form of private enterprises, the development for private enterprises is in highly demanded for any economy, which is the original purpose for doing the research.

\section{REFERENCES}

[1] Zuhui Huang, Xiaobo Zhang, \& Yunwei Zhu, "The Formation of Wenzhou Footwear Clusters: How Were the Entry Barriers Overcome?", International Association of Agricultural Economists Conference, August 2006, Retrieved from http://purl.umn.edu/25371

[2] Chunhong Su, \& Jian Wei, "The development differences on private economy: the comparison between Shandong province and Zhejiang province", Shandong Social Science, vol. 8, 2004

[3] Jun Liu, "The Contact between Northern\& Southern Enterprises and Government in Late Qing Dynasty\& the Republican period.", Research on Financial and Economic Issues, vol. 12, Dec. 2008.

[4] Yang Yiqing, \& Liu Shouye "The Entrepreneurship and the Relationship Between Politics and Commerce Exemplified by the Mechanism Formation of the Political and Business Relations in Zhejiang", JOURNAL OF NINGBO UNIVERSITY, vol. 32, Nov. 2019.

[5] Shandong province bureau of statistics, "Yearbook", 2019

[6] Zhejiang province bureau of statistics, "Yearbook", 2013-2019 